\title{
Efficient Utilization of Nursing Manpower during the COVID-19 Pandemic
}

\author{
Rajarajeswari Kuppuswamy ${ }^{1}$, Suresh K Sharma ${ }^{2}$
}

\begin{abstract}
Pandemics bring a significant crisis for the health care system and battle can only be swiftly won, if the army of health care workers is well prepared and efficiently utilized. Nurses are the major health care human resources, who play a key role in the management of COVID-19 as there are no definitive treatment and recovery largely depend on efficacious care. Therefore, it is essential to plan and utilize nursing manpower efficiently during the pandemics like COVID-19. There is a paucity of literature regarding the efficient utilization of nursing manpower during the COVID19 pandemic, because of its novice phenomenon. Therefore, the authors made a sincere attempt to present a comprehensive commentary on strategies for efficient utilization of nursing manpower for safety and quality of care. Key components of efficient utilization are the creation of three-tier pool of nurses, using minimalist approach in staffing rosters, relaxing nurse staffing norms to minimal, flexible shifts, three-layer relieving rosters for sufficient time for quarantine, adequate safety through the provision of high-quality personal protective equipment (PPE), training on infection prevention and control, environmental engineering for safety enhancement, hospital-based quarantine facility, avoidance of discrimination, motivation, and counseling for the nurses.

Keywords: Nursing personnel, Pandemic, Staffing.

Pondicherry Journal of Nursing (2020): 10.5005/jp-journals-10084-12145
\end{abstract}

\section{BACKGROUND}

A pandemic is "an epidemic occurring worldwide, or over a very wide area, crossing international boundaries and usually affecting a large number of people.." ${ }^{11}$ COVID-19 is a pandemic that has spread to more than 190 countries and still on the rise. It becomes a herculean task for the government and for the health care institutions to handle resources during a disease outbreak. If it is a pandemic, it becomes much more complicated. India is facing the deadly novel COVID-19 pandemic. As on 1st June 2020, more than $6,057,853$ cases have been reported worldwide and India has 190,535 confirmed cases. Maharashtra recorded the highest number of cases with a cumulative tally of 74,443 . The number of total cases were 24,563 in Tamil Nadu at the time of this article revision. Maharashtra accounts for the highest number of fatalities, followed by Gujarat, Madhya Pradesh, Delhi, and Andhra Pradesh. ${ }^{2}$

It is imperative that we need to address this issue of the pandemic with full zeal and preparedness. Resource deficit is a major concern, and especially, staff deficit plays a major role. In order to efficiently utilize health care human resources during the pandemic, meticulous planning and preparedness are required. Round the clock, $24 \times 7$ resources are required for effective handling of pandemic, where material resources may be exported; however, human resources cannot be exported in such crisis and they have a high risk of infection, the potential for stress, and mental health issues. Therefore, it is evident that there is a serious need to manage human resources judiciously. Otherwise, it is exceedingly difficult to win such a battle.

As per WHO checklist for influenza epidemic preparedness, the aim of the operational planning is to decrease the transmission of pandemic and number of new case occurrences along with decreasing hospital admissions and deaths. Apart from these, the major aims of careful planning of resources are to maintain essential services and to reduce the socioeconomic aftermath of a pandemic. $^{3}$

\footnotetext{
${ }^{1,2}$ College of Nursing, All India Institute of Medical Sciences, Rishikesh, Uttarakhand, India
}

Corresponding Author: Suresh K Sharma, College of Nursing, All India Institute of Medical Sciences, Rishikesh, Uttarakhand, India, Phone: +91 8475000293, e-mail: sk.aiims17@gmail.com

How to cite this article: Kuppuswamy R, Sharma SK. Efficient Utilization of Nursing Manpower during the COVID-19 Pandemic. Pon J Nurs 2020;13(2):39-42.

Source of support: Nil

Conflict of interest: None

Keeping in mind the above aims, it becomes mandatory to use nursing resources efficiently and intelligently, so that there is no shortage of nursing personnel throughout the pandemic management phases. We should remember to take care of the health and safety of staff when we plan for deployment to fight the pandemic.

\section{Nursing Manpower Deployment Administrative Control}

Pandemics demand more than the existing number of personnel for patient care. Two kinds of plans are to be prepared-one for contingency and the other for crisis. ${ }^{4}$ Nursing personnel from general wards and clinics are to be reassigned. Employees on long annual leave or sabbatical leave can be called back to duty. Retired nurses who are in good health can also be inducted for the fight against the pandemic. Nurses involved in non-COVID research and administrative work can be redistributed to COVID management areas. General duty nurses can be assigned with long shift duty (preferably 12-hour shift), thereby extra-nursing manpower in those areas can be used as resources for COVID management. ${ }^{5}$

(c) The Author(s). 2020 Open Access This article is distributed under the terms of the Creative Commons Attribution 4.0 International License (https://creativecommons. org/licenses/by-nc/4.0/), which permits unrestricted use, distribution, and non-commercial reproduction in any medium, provided you give appropriate credit to the original author(s) and the source, provide a link to the Creative Commons license, and indicate if changes were made. The Creative Commons Public Domain Dedication waiver (http://creativecommons.org/publicdomain/zero/1.0/) applies to the data made available in this article, unless otherwise stated. 
A brief summary of the strategic deployment of nursing manpower is given in Table 1.

Essentially, if we plan to have one-third of the staff to cater to the needs of the patients in the pandemic care areas, the rest of the

Table 1: Strategic utilization of nursing resources in COVID-19 pandemic

\begin{tabular}{|c|c|}
\hline Domains & Suggested strategies \\
\hline \multirow[t]{5}{*}{ Deployment of nurses } & Three-tier nursing personnel schedulin \\
\hline & $\begin{array}{l}\text { First tier-junior nurses, temporary } \\
\text { nurses, volunteer nurses, and } \\
\text { probationers }\end{array}$ \\
\hline & $\begin{array}{l}\text { Second tier-senior nurses and specia } \\
\text { nurses }\end{array}$ \\
\hline & $\begin{array}{l}\text { Third tier-nursing supervisors and } \\
\text { administrators }\end{array}$ \\
\hline & $\begin{array}{l}\text { Deployment in COVID area from tiers } \\
1 \text { and } 2 \text { in the ratio of } 4: 1 \text { and } 1 \text { from ti } \\
3 \text { each day }\end{array}$ \\
\hline \multicolumn{2}{|l|}{ Nurse-to-patient ratio } \\
\hline COVID-19ICUs & $\begin{array}{l}1: 3-6 \text { ( } 1: 1 \text { if the patient is on prone } \\
\text { ventilation) }\end{array}$ \\
\hline Isolation wards & 1:5-8 (noncritical patients) \\
\hline Non-COVID-19 ICUs & $1: 3$ \\
\hline Non-COVID-19 wards & $1: 8$ \\
\hline \multicolumn{2}{|l|}{ Length of shift ${ }^{(4)}$} \\
\hline COVID-19 ICUs & $\begin{array}{l}\text { 6-hour shift with 1-hour overlapping } \\
\text { (4 shifts) }\end{array}$ \\
\hline Isolation wards & 12-hour shift (2 shifts) \\
\hline Non-COVID-19 units & 8-hour shift (3 shifts) \\
\hline Shift rotation and & Three batches of personnel \\
\hline
\end{tabular}

First batch for 14 days, then quarantined

Second batch enters rotation for 14 days, then quarantined

Third batch enters and second batch goes for quarantine

Third batch goes for quarantine, first batch returns to duty

Training and capacity COVID-19 preparedness training sessions building

to be planned for all health care workers including donning and doffing of PPE, virtual orientation of the COVID care area, disinfection and cleaning, airway management, care of dead and nurses' responsibilities as a primary caregiver and secondary caregiver

Mental health, motivation and counseling

Motivational interactive talks with nursing personnel before inducting into the care of COVID-positive patients are mandatory. As and when needed during the rotation of after, counseling should be made available at easy reach of the personnel

Ethics of care during the Nurturing the ethical values of equity pandemic

staff can be spared if in case the first line gets quarantined. There should be a pool of nurses on call during the emergencies. The minimum number of nurses is required to be scheduled as the rest would be in backup schedule. As the elective surgeries would be postponed to a post-crisis period, these nursing personnel can be utilized for the nurse pool. In non-pandemic patient areas, intern nurses need to be pitched in, to deal with the crisis as suggested by the Ministry of Health and Family Welfare, Government of India. As their services are utilized in the non-pandemic areas, we would be in a better position to plan the deployment of nursing personnel for staffing in a pandemic area.

\section{Nurse Deployment in COVID-19 ICU}

Nurses from the other high-dependency units (HDUs) like medicine/ surgery/pediatric HDUs can be reassigned duties in intensive care units (ICUs) and ICU-trained nurses who work in other areas can be called to work in HDUs. ${ }^{5}$ The ideal 1:1 nurse-to-patient ratio in ICU may not be possible during the COVID pandemic; therefore, recently NHS has relaxed the nurse-to-patient ratio in COVID-19 ICU to up to 1:6.

Three tiers of nursing personnel should be planned. The first tier of nurses should ideally include junior nurses, temporary nurses, probationers, and volunteer nurses who should be stationed in the campus. The second tier should be senior nurses and specialist nurses. The third tier of nursing personnel should be nursing supervisors and administrators.

An ideal roster for COVID-19 ICU should include a mix of nursing personnel from each tier, keeping in mind one-third staffing rule during the pandemics. When the shift is scheduled, it should be according to the hospital's capacity and available workforce. It can be either 2 shifts of 12 hours each or 3 shifts of 8 hours each or 4 shifts of 6 hours per day. Six hours of continuous shift with 1-hour overlapping time may provide improved efficiency and provide a larger scope for nurse's health and safety as reported by Huang. ${ }^{6}$

\section{Nurse Scheduling in COVID Isolation Ward}

Stable COVID-19-positive patients are admitted in isolation ward specifically designed for COVID-19 pandemic. Nurses should be posted in isolation areas where COVID-19-positive patients are attended to, for 14-day duty, and then, they need to be quarantined for 14 days in quarantine accommodation which should be provided by the hospital. Later, those nurses can be posted in general areas so that they can visit their families and come from home if need be. ${ }^{7}$ In a set of guidelines prepared by Chennai-based researchers, it is suggested that a 15-day protocol for staff in three batches to be prepared wherein the first batch will take over 15 days, followed by the second batch. By this time, the first batch are to be sent to quarantine. When the third batch enter the duty schedule, the second batch will be sent for quarantine and, when they leave, the first batch will take over. ${ }^{8}$

\section{Staff Welfare}

The essential services should be made available for the staff on duty and on quarantine. The provision of transport services aid staff in comfort and safety. Appropriate PPE calculation and provision is the key element of safe staff scheduling. Nurses working in nonCOVID-19 areas also to be provided with protective equipment as there is a rise in infection among health care workers in these areas. Voluntary hydroxychloroquine (HCQ) prophylaxis should be made available for nurses who are posted in COVID-19 areas with 
informed consent. Food and snacks with beverage supply should be mandated for the working staff. Psychological counseling helps to boost the morale of nurses. Ensure that staff are made aware of the health insurance offered by the government for the workers involved in the management of pandemic patients. Hospital preparedness and response committee consists of hospital head, nursing superintendents, quality control team, hospital infection control committee team, and engineering team should be established for preparedness and training of staff which will in turn take care of the welfare of them during the pandemic. Furthermore, authors are of the opinion that nurses who are pregnant, $>65$ years of age, having chronic illnesses like cancer, uncontrolled diabetes, cystic fibrosis, chronic obstructive pulmonary disease (COPD), pulmonary tuberculosis, heart diseases, inborn errors of metabolism, or underwent solid organ transplantation, bone marrow or stem cell transplantation, immunosuppression therapies or any other condition which increases risk of viral infection should be spared from the active COVID-19 unit postings but may be utilized in non-COVID-19 or support work assignments. ${ }^{9}$

\section{Training and Preparedness for COVID-19}

Planned teaching and training sessions for the nurses on recent advancements in infection prevention and control, biomedical waste management, emergency management should be mandatory. In a study by Xu et al. in China, it was found that management strategy including staff training improved the effectiveness of COVID prevention and control. ${ }^{10}$ Refresher training courses enhance the confidence of the nurses to work efficiently. Intensive four-week training for nurses working in non-intensive areas to work in COVID19 ICU improves infection control and prevention and emergency management of patients. ${ }^{5}$ Training is a means of special protection to nursing personnel as it gives a scientific understanding of the disease and its prevention and control. ${ }^{6}$

\section{Mental Health and Counseling}

Health care workers especially those work in close proximity of the patient for an extended period of time may experience stress and extreme mental fatigue due to overburdening. All professionals must be mentally prepared for the mental dilemma due to pandemic and its consequences on the health of their own and their family. Support from peer and mental health experts will reduce the stressrelated issues in the nurses. Even after the crisis stage passes away, staff need to be supported and their heroic acts of supporting during the crisis must be appreciated. Working less effectively than expected (presenteeism) may also indicate mental disturbance. Early identification of stress and mental health challenges followed by appropriate counseling and support is a key to efficient combat of the pandemic. ${ }^{11}$ A study in China stated that there were stressrelated symptoms and depression in $73.4 \%$ and $50.7 \%$ of health care workers, respectively. ${ }^{12}$ Therefore, mental health support is vital. Sick employees should be encouraged to stay at home or quarantined at designated special accommodations. Whenever the employees are quarantined or stressed, they should have access to telecounseling services so that appropriate suggestions and counseling are provided without delay and their mental health maintained.

\section{Ethics during the Planning for a Pandemic}

A pandemic causes not only the disruption of the daily activities of the public but also the regular activities of the hospital. It causes stress on health care professionals. Quarantining nurses after specified hours of the duty in special accommodations puts them in undue stress as they seldom see their families.

Apart from the stress of quarantine and extended duty hours, there is an issue of social stigma these days in some parts of the country wherein the health care workers who are quarantined are treated like patients affected by the disease and are being denied of the basic necessities of living by the neighbors and house owners. ${ }^{13}$

Nurturing the ethical values of equity and trust are important. Nurses should equally treat all the patients with diseases and no kind of discrimination should be exhibited. Reciprocally, people should also trust the health care professionals and their sense of responsibility and care that is being provided. ${ }^{14}$

\section{Conclusion}

A well-designed control system for nursing personnel which can command and take full responsibility for allocating and scheduling nursing personnel is mandatory in tackling the pandemic crisis efficiently. The goal of staff planning should be achieved keeping in mind the health and safety of nurses and all other health care workers. If nursing staff are scheduled efficiently in the prepreparedness phase of the pandemic, the management of cases during the actual impact phase would be successful. At present, in India, the need of the hour is nurse leaders who can plan a perfect strategy to fill the existing knowledge gap, to allocate and mobilize resources, and to motivate and empower nurses. In each state of our country, if nurse leaders are rightly identified and entrusted with the responsibility of crisis intervention, we would definitely be able to contain the disease spread and safeguard the health care workers.

\section{References}

1. Last JM. A dictionary of epidemiology. 4th ed., New York: Oxford University Press; 2001.

2. Available from https://www.who.int/emergencies/diseases/novelcoronavirus-2019.

3. WHO. Checklist for influenza epidemic preparedness. WHO/CDS/ CSR/GIP/2005.4. Geneva: World Health Organization; 2005.

4. Wang H, Feng J, Shao L, Wei J, Wang X, Xu X, et al. Contingency management strategies of the nursing department in centralized rescue of patients with coronavirus disease 2019. Int J Nurs Sci 2020;7(2):139-142. DOI: 10.1016/j.jijnss.2020.04.001.

5. Lee CC, Thampi S, Lewin B, Lim TJ, Rippin B, Wong WH, et al. Battling COVID-19: critical care and peri-operative healthcare resource management strategies in a tertiary academic medical centre in Singapore. Anaesthesia 2020;75(7):861-871. DOI: 10.1111/anae.15074.

6. Huang L, Lin G, Tang L, Yu L, Zhou Z. Special attention to nurses' protection during the COVID-19 epidemic. Crit Care 2020;24(1):120. DOI: 10.1186/s13054-020-2841-7.

7. Dutta A. Coronavirus: Nurses ask for rotation of duty after 14-day shift in Covid wards. Hindustan Times [Internet]. 2020 Apr 12 [cited 2020 Apr 25]. Available from: https://www.hindustantimes.com/ delhi-news/nurses-ask-for-rotation-of-duty-after-14-day-shift-incovid-wards/story-8NWsAOnigNelmVRvimhyKJ.html.

8. Selvakumar K, Gopi V, SMH FS, Chindhiha S, Divya S. Hospital preparedness for emergency in India (hope-I) to combat COVID-19 outbreaks. Stud Indian Place Names 2020;40(70):4226-4236.

9. World Health Organization [Internet]. Coronavirus disease (COVID19) outbreak: rights, roles and responsibilities for the health workers, including key considerations for occupational safety and health: Interim guidance. 2020 March 19 [cited 2020 April 3]. Available from: https://apps.who.int/iris/handle/10665/331510. License: CC BY-NC-SA $3.0 \mathrm{IGO}$ 
10. Xu C, Jin J, Song J, Yang Y, Yao M, Zhang Y, et al. Application of refined management in the prevention and control of coronavirus disease 2019 epidemic in non-isolated areas of a general hospital. Inter J Nurs Sci 2020;7(2):143-147. DOI: 10.1016/j.ijnss.2020.04.003.

11. Greenberg N, Docherty M, Gnanapragasam S, Wessely S. Managing mental health challenges faced by healthcare workers during COVID19 pandemic. BMJ 2020;368:m1211. DOI: 10.1136/bmj.m1211.
12. Chen $Q$, Liang $M$, Li Y, Guo J, Fei D, Wang L, et al. Mental health care for medical staff in China during the COVID-19 outbreak. The lancet. Psychiatry 2020;7(4):e15-e16. DOI: 10.1016/S2215-0366(20)30078-X.

13. Torda A. Ethical issues in pandemic planning. Med J Australia 2006;185(S10):S73-S76. DOI: 10.5694/j.1326-5377.2006.tb00713.x.

14. Chetterje P. Gaps in India's preparedness for COVID-19 control. Lancet Infect Dis 2020;20(5):544. DOI: 10.1016/S1473-3099(20)30300-5. 